\title{
Mendeskripsikan Keterampilan Proses Sains Siswa melalui Kegiatan Praktikum Viskositas di SMAN 1 Muaro Jambi
}

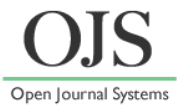

\author{
Riska Fitriani", Diki Chen, Shella Maryani, Febri Tia Aldila, Agnes Aktapianti Br.Ginting, \\ Nanda Hasbullah Sehab, Mashelin Wulandari \\ Program Studi Pendidikan Fisika,Universitas jambi, Jambi 36123 \\ *Email: riskafitriani04.rf@gmail.com
}

DOI: https://doi.org/10.33369/pendipa.5.2.173-179

\begin{abstract}
The purpose of this study was to describe the science process skills of the XI grade science students at public high school (SMAN 1) Muaro Jambi through the viscosity material physics practicum. The researcher used a descriptive research with a quantitative approach. This research was conducted in November 2020. The population in this study were all students of class XI IPA 2 at SMAN 1 Muaro Jambi, totaling 30 students and the data were collected using a total sampling technique. In this study, a research instrument was used in the form of an observation sheet of science process skills that had been validated by an expert validator, then the data from the scientific process skills obtained were analyzed using descriptive statistics. The results of the research on students 'science process skills in viscosity practicum showed that the level of students' science process skills was at a very good level, students were able to do experiments skillfully and correctly where students were skilled in observing, classifying, communicating, measuring, and predicting, while in concluding skills fall into the good category. The percentage of very good categories is $46.7 \%$ observation skills, $43.3 \%$ classification skills, 33.3\% communication skills, $33.3 \%$ measuring skills and $26.7 \%$ predictive skills, while $33.3 \%$ concluding skills are categorized as good..
\end{abstract}

Keywords: Indicator; science process skills; practice; physics; viscosity.

\begin{abstract}
ABSTRAK
Tujuan dari penelitian ini adalah untuk mendeskripsikan keterampilan proses sains siswa IPA kelas XI di SMAN 1 Muaro Jambi melalui kegiatan praktikum fisika materi viskositas. Jenis penelitian yang digunakan peneliti adalah jenis penelitian deskriptif dengan pendekatan kuantitatif. Penelitian ini dilakukan pada bulan November tahun 2020. Populasi dalam penelitian ini adalah seluruh siswa kelas XI IPA 2 di SMAN 1 Muaro Jambi yang berjumlah 30 orang siswa dan data dikumpulkan menggunakan teknik total sampling. Dalam penelitian ini digunakan instrumen penelitian berupa lembar observasi (LO) keterampilan proses sains (KPS) yang sudah divalidasi oleh validator ahli, kemudian data dari keterampilan proses sains yang diperoleh dianalisis dengan menggunakan statistik deskriptif. Hasil penelitian keterampilan proses sains siswa dalam praktikum viskositas menunjukan bahwa tingkat keterampilan proses sains siswa tergolong pada tingkatan yang sangat baik, siswa mampu melakukan percobaan secara terampil dan benar dimana siswa terampil dalam mengobservasi, mengklasifikasi, mengkomunikasikan, mengukur, dan memprediksi, sedangkan pada keterampilan menyimpulkan masuk dalam kategori baik. Persentase berkategori sangat baik pada keterampilan observasi 46,7\%, keterampilan klasifikasi 43,3\%, keterampilan mengkomunikasikan 33,3\%, keterampilan mengukur 33,3 \% dan keterampilan memprediksi 26,7\%, sedangkan keterampilan menyimpulkan $33,3 \%$ berkategori baik.
\end{abstract}

Kata kunci: Indikator; keterampilan proses sains; praktikum; fisika; viskositas. 


\section{PENDAHULUAN}

Fisika adalah ilmu yang bertujuan mendidik siswa agar dapat berpikir secara kritis, logis, memiliki sifat obyektif, dan disiplin dalam menyelesaikan berbagai permasalahan kehidupan sehari-hari sehingga fisika perlu dipelajari dan diaplikasikan (Purwanto et al, 2016). Dalam jenjang SMA, Fisika merupakan salah satu mata pelajaran wajib dalam kegiatan pembelajaran namum masih banyak siswa yang belum mendapatkan nilai yang memuaskan (Kurnia et al, 2016) dikarenakan fisika dikategorikan sebagai mata pelajaran yang kurang disukai oleh banyak siswa (Astalini et al, 2019). Cukup banyak siswa SMA Negeri se-Kota Jambi yang mengalami kesulitan dalam memahami materi pembelajaran fisika karena banyaknya rumusrumus sehingga siswa sukar untuk memahami materi yang diajarkan oleh guru (Setia et al, 2017), selain itu siswa juga harus memahami dan mengusasi berbagai rumus dalam fisika kemudian mengaplikasikan dalam perhitungan (Oktaviana et al, 2016) serta siswa sulit memahami konsep materi karena memuat hal-hal yang bersifat abstrak (Priyadi et al, 2019).

Materi fisika yang dianggap sulit, menyebabkan kurangnya keaktifan belajar dari siswa (Sipahutar, Hendri dan Dani, 2018). Hal ini ditunjukkan dari rata-rata hasil belajar siswa yang masih begitu memprihatinkan (Pasaribu, Hendri dan Susanti, 2017). Berdasarkan hasil analisis kebutuhan yang dilakukan melalui wawancara, siswa cenderung menginginkan proses pembelajaran yang lebih bervariasi (Taqwa et al, 2019) karena pelaksanaan proses pembelajaran kadangkala membosankan bagi siswa, oleh karena itu seorang guru dituntut untuk lebih profesional sehingga dapat membuat pembelajaran menjadi lebih menyenangkan dan tidak membosankan (Pathoni et al, 2015) misalnya dengan memberikan pengalaman belajar langsung pada siswa (Maulana et al, 2018). Salah satu kegiatan pembelajaran yang dapat memberikan pengalaman langsung pada siswa adalah melalui kegitan praktikum. Praktikum mampu meningkatkan keterampilan proses sains dan keahlian siswa dalam pengamatan, sebagai sarana berlatih dalam menggunakan peralatan, dan dapat mengembangkan rasa ingin tahu, aktif, kreatif, inovatif, serta menumbuhkan kejujuran ilmiah pada diri siswa (Khamidah \& Aprilia, 2014).

Keterampilan proses sains diartikan sebagai kemampuan peserta didik dalam menerapkan metode ilmiah untuk memahami, mengembangkan sains dan menemukan ilmu pengetahuan (Lestari \& Diana, 2018). Keterampilan proses sains siswa sangat penting dilatih dan dikembangkan dalam proses pembelajaran karena hal ini merupakan kompetensi dasar untuk mengembangkan sikap ilmiah dan keterampilan siswa dalam memecahkan masalah, sehingga dapat membentuk pribadi yang kreatif, inovatif, kritis dan kompetitif dalam persaingan global di masyarakat (Turiman et al, 2012). Dalam penelitian ini, peneliti mengukur keterampilan proses sains dasar siswa IPA kelas XI di SMAN 1 Muaro Jambi. Keterampilan proses sains dasar tersebut meliputi: observasi, klasifikasi, komunikasi, pengukuran, kesimpulan, dan prediksi (Darmaji et al, 2018a).

Berdasarkan uraian di atas, dapat disimpulkan bahwa pentingnya pengembangan keterampilan proses sains siswa pada tingkat pendidikan harus terus dilakukan karena pada kenyataannya masih ditemukan siswa dan guru di lapangan yang belum menguasai keterampilan proses sains (Darmaji et al, 2018b). Oleh karena itu, perlu dilakukan penelitian dengan tujuan adalah untuk mendeskripsikan tingkat Keterampilan Proses Sains Siswa IPA Kelas XI di SMA Negeri 1 Muaro Jambi melalui kegiatan praktikum fisika materi viskositas.

Diharapkan hasil dari penelitian ini dapat digunakan sebagai gambaran atau sebagai bahan evaluasi untuk sekolah dan guru fisika agar dapat mengetahui tingkat keterampilan proses sains dari siswanya dan selanjutnya dapat meningkatkan keterampilan proses sains siswa disekolah tersebut. Sebelumnya sudah dilakukan penelitian yang dilakuakan oleh Yaspin Yolanda dimana penelitiannya menunjukkan bahwa terdapat peningkatan keterampilan proses sains siswa pendidikan fisika pada praktikum lisrtrik magnet. Hal yang membedakan penelitiaan yang dilakukan Yaspin Yolanda dengan penelitian yang saya lakukan yaitu terdapat pada materi praktikum, saya melakukan penelitian pada materi viskositas sedangkan penelitian 
sebelumnya melakukan penelitian pada materi listrik magnet.

\section{METODE PENELITIAN}

Penelitian ini merupakan jenis penelitian deskriptif dengan pendekatan kuantitatif tentang Keterampilan Proses Sains (KPS) siswa melalui kegiatan praktikum fisika materi viskositas. Penelitian ini dilakukan pada bulan November tahun 2020. Populasi dalam penelitian ini adalah seluruh siswa kelas XI IPA 2 di SMAN 1 Muaro Jambi yang berjumlah 30 orang siswa dan data dikumpulkan menggunakan teknik total sampling. Pujianto (2015) mengatakan bahwa teknik ini disebut teknik total sampling, karena populasi sekaligus sebagai sampel penelitian. Sampel dari 30 siswa dibentuk menjadi kelompok-kelompok kecil dengan masing-masing kelompok berjumlah tiga orang siswa agar pemanfaatan waktu lebih efektif dan setiap siswa mendapat kesempatan yang sama untuk melakukan percobaan, ini sesuai dengan tujuan penelitian yaitu mendeskripsikan keterampilan proses sains siswa IPA pada praktikum fisika materi viskositas di SMA Negeri 1 Muaro Jambi.

Penelitian menggunakan instrumen penelitian berupa lembar observasi (LO) keterampilan proses sains (KPS) yang sudah divalidasi oleh validator ahli dan pengisian lembar observasi dibantu oleh observer yang berjumlah 15 orang. Indikator yang diamati dalam penelitian ini adalah keterampilan proses sains dasar yang dimiliki siswa saat melakukan kegiatan praktikum viskositas, kemudian data keterampilan proses sains yang diperoleh dianalisis dengan menggunakan statistik deskriptif. Indikator keterampilan proses sains dasar yang diukur dalam penelitian ini yaitu melakukan observasi, mengklasifikasi, mengkomunikasikan, mengukur, menyimpulkan dan memprediksi hasil dari praktikum yang dilakukan. Persentase untuk setiap indikator dicari dan dinyatakan dalam 4 kategori, yaitu kategori Sangat Tidak Baik (STB), Tidak Baik (TB), Baik (B), dan Sangat Baik (SB), kemudian dicari intervalnya untuk masing-maisng indikator lalu dinyatakan dalam beberapa kategori seperti ditunjukkan pada Tabel 1, Tabel 2, Tabel 3, Tabel 4, Tabel 5, dan Tabel 6 mengenai kategori penguasaan keterampilan proses sains (KPS) siswa pada enam indikator KPS dasar sebagaimana yang telah disebutkan di atas

Tabel 1. Kategori Penguasaan Keterampilan Proses Sains Siswa pada Indikator Mengamati.

\begin{tabular}{lcc}
\hline No. & Interval & Kategori \\
\hline 1. & $19,00-33,25$ & Sangat Tidak Baik \\
2. & $33,26-47,50$ & Tidak Baik \\
3. & $47,51-61,75$ & Baik \\
4. & $61,76-76,00$ & Sangat Baik \\
\hline
\end{tabular}

Tabel 2. Kategori Penguasaan Keterampilan Proses Sains Siswa pada Indikator Mengklasifikasikan

\begin{tabular}{lrc}
\hline No. & Interval & Kategori \\
\hline 1. & $9,00-15,75$ & Sangat Tidak Baik \\
2. & $15,76-22,50$ & Tidak Baik \\
3. & $22,51-29,25$ & Baik \\
4. & $29,26-36,00$ & Sangat Baik \\
\hline
\end{tabular}

Tabel 3. Kategori Penguasaan Keterampilan Proses Sains Siswa pada Indikator Mengkomunikasikan

\begin{tabular}{lcc}
\hline No. & Interval & Kategori \\
\hline 1. & $11,00-19,25$ & Sangat Tidak Baik \\
2. & $19,26-27,50$ & Tidak Baik \\
3. & $27,51-35,75$ & Baik \\
4. & $35,76-44,00$ & Sangat Baik \\
\hline
\end{tabular}

Tabel 4. Kategori Penguasaan Keterampilan Proses Sains Siswa pada Indikator Mengukur

\begin{tabular}{lcc}
\hline No. & Interval & Kategori \\
\hline 1. & $6,00-10,5$ & Sangat Tidak Baik \\
2. & $10,6-15,0$ & Tidak Baik \\
3. & $15,1-19,5$ & Baik \\
4. & $19,6-24,00$ & Sangat Baik \\
\hline
\end{tabular}

Tabel 5. Kategori Penguasaan Keterampilan Proses Sains Siswa pada Indikator Menyimpulkan

\begin{tabular}{lcc}
\hline No. & Interval & Kategori \\
\hline 1. & $13,00-22,75$ & Sangat Tidak Baik \\
2. & $22,76-32,50$ & Tidak Baik \\
3. & $32,51-42,25$ & Baik \\
4. & $42,26-52,00$ & Sangat Baik \\
\hline
\end{tabular}


Tabel 6. Kategori Penguasaan Keterampilan Proses Sains Siswa pada Indikator Memprediksi

\begin{tabular}{lcc}
\hline No. & & Kategori \\
\hline 1. & $1,00-1,75$ & Sangat Tidak Baik \\
2. & $1,76-2,50$ & Tidak Baik \\
3. & $2,51-3,25$ & Baik \\
4. & $3,26-4,00$ & Sangat Baik \\
\hline
\end{tabular}

\section{HASIL DAN PEMBAHASAN}

Menurut Ningsi \& Nasih (2020) keterampilan proses sains merupakan keterampilan yang harus dimiliki oleh setiap peserta didik. Pada penelitian ini peneliti mendeskripsikan tingkat KPS siswa IPA kelas XI di SMA Negeri 1 Muaro Jambi melalui praktikum fisika materi viskositas. Peneliti menggunakan enam indikator KPS dasar yang meliputi: melakukan observasi, mengklasifikasi, mengkomunikasikan, mengukur, menyimpulkan dan melakukan prediksi. Hasil yang diperoleh peneliti disajikan pada tabel berikut:

Tabel 7. Deskripsi KPS Dasar dengan Indikator Observasi pada Praktikum Fisika Materi

\begin{tabular}{ccc}
\multicolumn{3}{c}{ Viskositas } \\
\hline \multirow{3}{*}{ Klasifikasi } \\
Indikator & kategori & $\%$ \\
& & \\
& Sangat Tidak baik & 3,3 \\
& Tidak Baik & 10,0 \\
Observasi & Baik & 40,0 \\
& Sangat Baik & 46,7 \\
& Total & 100,0 \\
\hline Mean & \multicolumn{2}{c}{56,90} \\
\hline Median & \multicolumn{2}{c}{61,00} \\
\hline Min & \multicolumn{2}{c}{28,00} \\
\hline Max & \multicolumn{2}{c}{72,00} \\
\hline
\end{tabular}

Berdasarkan hasil penelitian yang telah dilakukan, diperoleh hasil keterampilan proses sains siswa dominan berkategori sangat baik, karena hampir sebagian besar siswa sudah sangat terampil dan tepat dalam melakukan praktikum fisika materi viskositas dengan indikator keterampilan proses sains dasar yaitu melakukan observasi, mengklasifikasi, mengkomunikasikan, mengukur dan melakukan prediksi, sedangkan dalam keterampilan menyimpulkan berkategori baik. Menurut Sitompul et al (2018), pendidikan yang baik dapat dilihat dari kemandirian dan semangat siswa dalam belajar. Seperti yang dikatakan oleh Dari \& Nasih (2020) bahwa ini terbukti dari hasil praktikum yang dilakukan oleh siswa, di mana siswa cendrung aktif dan terampil dalam melakukan kegiatan praktikum.

Tabel 8. Deskripsi KPS Dasar dengan Indikator Klasifikasi pada Praktikum Fisika Materi

\begin{tabular}{|c|c|c|}
\hline \multicolumn{3}{|c|}{ Klasifikasi } \\
\hline Indikator & kategori & $\%$ \\
\hline Viskositas & $\begin{array}{c}\text { Sangat Tidak baik } \\
\text { Tidak Baik } \\
\text { Baik } \\
\text { Sangat Baik } \\
\text { Total }\end{array}$ & $\begin{array}{l}10,0 \\
13,3 \\
40,0 \\
33,3 \\
43,3\end{array}$ \\
\hline Mean & 25,67 & \\
\hline Median & 25,50 & \\
\hline Min & 14,00 & \\
\hline Max & 32,00 & \\
\hline
\end{tabular}

Tabel 9. Deskripsi KPS Dasar dengan Indikator Mengkomunikasikan pada Praktikum Fisika

\begin{tabular}{ccc}
\multicolumn{3}{c}{ Materi Viskositas } \\
\hline \multirow{3}{*}{ Klasifikasi } \\
Indikator & kategori \\
\hline \multicolumn{3}{c}{ Mengkomu- } \\
nikasikan & Sangat Tidak baik & 16,7 \\
& Tidak Baik & 23,3 \\
& Baik & 26,7 \\
& Sangat Baik & 33,3 \\
& Total & 43,3 \\
\hline Mean & 29,50 \\
\hline Median & 30,00 \\
\hline Min & \multicolumn{2}{c}{14,00} \\
\hline Max
\end{tabular}

Pada indikator KPS dasar melakukan observasi, diperoleh persentase sebesar $46,7 \%$ dari 30 siswa tergolong dalam kategori sangat baik dalam melakukan observasi. Keterampilan 
observasi ini sangat penting untuk dikuasai oleh setiap siswa karena kemampuan observasi atau mengamati ini merupakan keterampilan paling mendasar yang dapat mendukung penguasaan keterampilan lainnya.

Tabel 10. Deskripsi KPS Dasar dengan Indikator Mengukur pada Praktikum Fisika Materi

\begin{tabular}{ccc}
\multicolumn{3}{c}{ Viskositas } \\
\hline \multirow{3}{*}{ Klasifikasi } \\
\multicolumn{3}{c}{ kategori } \\
& Sangat Tidak baik & 16,7 \\
& Tidak Baik & 20,0 \\
Mengukur & Baik & 33,3 \\
& Sangat Baik & 30,0 \\
& Total & 100,0 \\
\hline Mean & \multicolumn{2}{c}{16,00} \\
\hline Median & 16,00 \\
\hline Min & \multicolumn{2}{c}{8,00} \\
\hline Max & \multicolumn{2}{c}{21,00} \\
\hline
\end{tabular}

Tabel 11. Deskripsi KPS Dasar dengan Indikator Menyimpulkan pada Praktikum Fisika Materi

\begin{tabular}{|c|c|c|}
\hline \multicolumn{3}{|c|}{ Klasifikasi } \\
\hline Indikator & kategori & $\%$ \\
\hline $\begin{array}{l}\text { Menyim- } \\
\text { pulkan }\end{array}$ & $\begin{array}{c}\text { Sangat Tidak baik } \\
\text { Tidak Baik } \\
\text { Baik } \\
\text { Sangat Baik } \\
\text { Total }\end{array}$ & $\begin{array}{c}20,0 \\
16,7 \\
33,3 \\
30,0 \\
100,0\end{array}$ \\
\hline Mean & 34,10 & \\
\hline Median & 34,00 & \\
\hline Min & 20,00 & \\
\hline Max & 46,00 & \\
\hline
\end{tabular}

Pada indikator KPS dasar melakukan klasifikasi, diperoleh persentase sebesar 43,3\% dari 30 siswa tergolong dalam kategori sangat baik dalam melakukan klasifikasi, hal ini dapat dilihat saat siswa mampu mengklasifikasikan karakteristik data percobaan viskositas, mengklasifikasikan karakteristik data percobaan bola padat 1 pada zat cair 1 dengan jarak d yang sama, mengklasifikasikan karakteristik data percobaan bola padat 2 pada zat cair 1 dengan jarak d yang sama, mengklasifikasikan karakteristik data percobaan bola padat 1 pada zat cair 2 dengan jarak d yang sama, mengklasifikasikan karakteristik data percobaan bola padat 2 pada zat cair 2 dengan jarak d yang sama, mengklasifikasikan karakteristik data percobaan bola padat 1 pada zat cair 1 dengan jarak d yang yang berubah-ubah, mengklasifikasikan karakteristik data percobaan bola padat 2 pada zat cair 1 dengan jarak d yang yang berubah-ubah, mengklasifikasikan karakteristik data percobaan bola padat 1 pada zat cair 2 dengan jarak d yang yang berubahubah, dan mengklasifikasikan karakteristik data percobaan bola padat 2 pada zat cair 2 dengan jarak d yang yang berubah-ubah.

Tabel 12. Deskripsi KPS Dasar dengan Indikator Prediksi pada Praktikum Fisika Materi Viskositas

\begin{tabular}{|c|c|c|}
\hline \multicolumn{3}{|c|}{ Klasifikasi } \\
\hline Indikator & kategori & $\%$ \\
\hline \multirow{5}{*}{ Prediksi } & Sangat Tidak baik & 23,3 \\
\hline & Tidak Baik & 20,0 \\
\hline & Baik & 26,7 \\
\hline & Sangat Baik & 30,0 \\
\hline & Total & 100,0 \\
\hline Mean & 2,63 & \\
\hline Median & 3,00 & \\
\hline Min & 1,00 & \\
\hline Max & 4,00 & \\
\hline
\end{tabular}

Kemudian pada indikator KPS dasar mengkomunikasikan, diperoleh persentase sebesar 33,3\% dari 30 siswa tergolong dalam kategori sangat baik dalam melakukan komunikasi, dimana indikator kps dasar mengkomunikasikan dapat dilihat saat siswa mampu mengutarakan ketelitian dan batas ukur mikrometer sekrup yang akan digunakan, mengutarakan ketelitian dan batas ukur neraca ohauss yang akan digunakan, membaca grafik hubungan variabel untuk penentuan koefisien viskositas dan mengutarakan yang terjadi jika jarak di diubah-ubah. 
Pada indikator KPS dasar yaitu mengukur, diperoleh persentase sebesar 33,3\% dari 30 siswa yang tergolong dalam kategori sangat baik dalam melakukan kegiatan mengukur, hal ini dapat dilihat saat siswa mampu mencari kalibrasi dan ketelitian pada neraca ohaus, mengukur jari-jari bola padat dengan menggunakan mikrometer sekrup, mengukur massa masing-masing bola padat dengan menggunakan neraca ohauss, mengukur massa masing-masing zat cair dengan menggunakan nerca ohauss, mengukur jarak karet gelang pertama ke karet gelang kedua (d), dan mengukur waktu tempuh bola dalam zat cair.

Pada indikator KPS dasar menyimpulkan, diperoleh persentase sebesar 33,3\% dari 30 siswa tergolong dalam kategori baik dalam melakukan penarikan kesimpulan terkait praktikum yang dilakukan. Dan pada indikator KPS dasar melakukan prediksi, diperoleh persentase sebesar $30,0 \%$ dari 30 siswa tergolong dalam kategori sangat baik dalam melakukan prediksi, dimana indikator KPS dasar melakukan prediksi dapat dilihat saat siswa mampu mengutarakan koefisien viskositas zat cair.

Nugraha et al (2017) menjelaskan bahwa keterampilan proses sains melibatkan kemampuan kognitif, keterampilan psikomotor, dan sosial yang apabila diterapkan dalam proses pembelajaran kepada siswa akan menjadikan pembelajaran sains menjadi lebih bermakna. Berdasarkan hasil penelitian, keterampilan proses sains dasar siswa SMAN 1 Muaro Jambi berkategori sangat baik, dimana siswa sudah sangat terampil dan benar dalam melakukan praktikum.

\section{KESIMPULAN}

Berdasarkan hasil penelitian yang telah dilakukan dan mendeskripsikan besar persentase sebaran KPS siswa IPA di SMA Negeri 1 Muaro Jambi pada praktikum fisika materi viskositas maka indikator KPS dasar yang dimiliki siswa masuk dalam kategori sangat baik yaitu siswa mampu melakukan obsevasi, mengklasifikasikan, mengkomunikasian, mengukur, dan melakukan prediksi, sedangkan keterampilan menyimpulkan masuk dalam kategori baik. Dengan demikian, siswa SMA Negeri 1 Muaro jambi sudah sangat terampil dan tepat dalam melakukan praktikum fisika materi viskositas.

\section{DAFTAR PUSTAKA}

Astalini., Kurniawan, D.A., Perdana, R., \& H. Pathoni. (2019). Identifikasi sikap peserta didik terhadap mata pelajaran fisika di sekolah menengah atas negeri 5 Kota Jambi, Unnes Physics Education Journal, 8(1), 34-43.

Dari, R.W., \& Nasih, N.R. (2019). Identifikasi tingkat KPS mahasiswa praktikum pembiasan kaca plan paralel menggunakan panduan praktikum berbasis e-modul, JIFP (Jurnal Ilmu Fisika dan Pembelajarannya), 3(2), 47-57.

Darmaji., Astalini., Rahayu, A., \& Maison. (2018a). Pengembangan penuntun praktikum fisika berbasis keterampilan proses sains menggunakan model problem solving, EDUSAINS, 10(01), 84-96.

Darmaji., Kurniawan, D.A., Parasdila, H., \& Irdianti. (2018b). Deskripsi keterampilan proses sains mahasiswa pada materi termodinamika, Berkala Ilmiah Pendidikan Fisika, 6(3), 345-353.

Khamidah, N., \& Aprilia, N. (2014). Evaluasi program pelaksanaan praktikum biologi kelas xi sma se-kecamatan umbulharjo yogyakarta semester ii tahun ajaran 2013/2014, Jupemasi-Pbio, 1 (1), 5-7.

Kurnia, N., Hendri, M., \& Pathoni, H. (2016). Hubungan persepsi dengan hasil belajar fisika siswa kelas X Mia di SMA negeri 4 Kota Jambi dan sma negeri 11 kota jambi, Jurnal EduFisika, 01(02), 55-63.

Lestari, M.Y., \& Diana, N. (2018). Keterampilan proses sains (KPS) pada pelaksanaan praktikum fisika dasar I, Indonesian Journal of Science and Mathematics Education, 01(1), 49-54.

Maulana, R., Jufrida., \& Pathoni. (2018). Upaya meningkatkan pemahaman konsep siswa menggunakan discovery based learning dengan bantuan LKS digital materi fluida dinamik kelas XI SMAN 11 Kota, Gravity: Jurnal Ilmiah Penelitian dan Pembelajaran Fisika, 4 (2), 67-81.

Ningsi, A.P., \& Nasih, N.R. (2020). Mendeskripsikan keterampilan proses sains mahasiswa pendidikan fisika Universitas Jambi pada materi pembiasan pada lensa cembung dengan menggunakan 
e-modul, EKSAKTA: Jurnal Penelitian dan Pembelajaran MIPA, 5(1), 35-43.

Nugraha, A. J., Suyitno, H., \& Susilaningsih, E. (2017). Analisis kemampuan berpikir kritis ditinjau dari keterampilan proses sains dan motivasi belajar melalui model PBL, Journal of Primary Education, 6(1), 35-43.

Oktaviana, D., Jufrida., \& Darmaji. (2016). Penerapan RPP berbasis multiple intelligences untuk meningkatkan aktivitas dan hasil belajar fisika siswa pada materi kalor dan perpindahan kalor Kelas X Mia 4 SMA Negeri 3 Kota Jambi, Jurnal EduFisika, 01(01), 7-12.

Pasaribu, D.S., Hendri, M., \& Susanti, N. (2017). Upaya meningkatkan minat dan hasil belajar fisika siswa dengan menggunakan model pembelajaran talking stick pada materi listrik dinamis di kelas X SMAN 10 Muaro Jambi, Jurnal EduFisika, 02(01), 61-69.

Pathoni, H., Rohati., \& Nazarudi. (2015). Peningkatan pemahaman konsep fisika dan aktifitas mahasiswa dengan model pembelajaran inquiry terbimbing media animasi, Jurnal Inovasi dan Pembelajaran Fisika, 2 (2), 119-122.

Priyadi, R., Maison., dan Kurniawan, W. (2019). Pengembangan kuis interaktif pembelajaran fisika pada materi hukum newton tentang gravitasi dengan menggunakan program wondersharequiz creator 4.5.1. Tesis. Universitas Jambi. Jambi.

Pujianto, A. (2015). Profil kondisi fisik dan keterampilan teknik dasar atlet tenis meja usia dini di kota semarang, Journal of Physical Education, Health and Sport, 2(1), 38-43.
Purwanto, A. K., Hendri, M., \& Susanti, N. (2016). Studi perbandingan hasil belajar siswa menggunakan media phet simulations dengan alat peraga pada pokok bahasan listrik magnet di kelas IX SMPN 12 Kabupaten Tebo, Jurnal EduFisika, 01(01), 22-27.

Setia, M.O., Susanti, N., \& Kurniawan, M. (2017). Pengembangan media pembelajaran dengan menggunakan adobe flash cs 6 pada materi hukum newton tentang gerak dan penerapannya, Jurnal EduFisika, 02(02), 42-57.

Sipahutar, M., Hendri, M., \& Dani, R. (2018). Model discovery learning berbantuan media adobe flash cs 6 pada materi hukum newton, Jurnal Edufisika, 3(2), 59-65.

Sitompul, R. S., Astalini., \& Alrizal.(2018). Deskripsi motivasi belajar fisika siswa kelas X MIA di SMAN 9 Kota Jambi., Edufisika, 2(3):22-31.

Taqwa, M.R.A., Faizah, R., \& Rivaldo, L. (2019). Pengembangan lembar kerja mahasiswa berbasis poe dan kemampuan berpikir kritis mahasiswa pada topik fluida statis, Edufisika: Jurnal Pendidikan Fisika, 4(1), 6-13.

Turiman. P., Omar. J., Daud. A. M., \& Osman. K. (2012). Membina keterampilan abad 21 melalui keaksaraan ilmiah dan keterampilan proses sains, Ilmu Sosial Dan Perilaku Procedia, 59: 110-116.

Yolanda, Y. (2019). Profil keterampilan proses sains (KPS) mahasiswa fisika pada materi listrik magnet. JIPFRI (Jurnal Inovasi Pendidikan Fisika dan Riset Ilmiah), 3(2), 70-78. 